\title{
Constrained Layer Damper Modelling and Performance Evaluation for Eliminating Squeal Noise in Trams
}

\author{
Inaki Merideno, ${ }^{1}$ Javier Nieto, ${ }^{2}$ Nere Gil-Negrete, ${ }^{1}$ Aitor Landaberea, ${ }^{3}$ and Jon Iartza ${ }^{3}$ \\ ${ }^{1}$ CEIT and Tecnun, University of Navarra, Manuel de Lardizabal 15, 20018 San Sebastián, Spain \\ ${ }^{2}$ CEIT, Manuel de Lardizabal 15, 20018 San Sebastián, Spain \\ ${ }^{3}$ CAF, Jose Miguel Iturrioz 26, 20200 Beasain, Spain
}

Correspondence should be addressed to Inaki Merideno; imerideno@ceit.es

Received 9 October 2013; Accepted 6 February 2014; Published 4 March 2014

Academic Editor: Peijun Xu

Copyright (C) 2014 Inaki Merideno et al. This is an open access article distributed under the Creative Commons Attribution License, which permits unrestricted use, distribution, and reproduction in any medium, provided the original work is properly cited.

\begin{abstract}
This paper presents the modelling and design of a constrained layer damper to eliminate squeal noise in a particular tram. Even though resilient wheels are installed in every bogie, squeal noise is generated at the frequency of $780-800 \mathrm{~Hz}$ due to the small radius curves that the tram has to draw. Tuned constrained layer dampers provide a solution to this particular problem. Butyl rubber is chosen as the viscoelastic material for the damper, and conventional steel is used for the metallic sheets. The modelling approach and the final design of the damper are presented, together with evaluation of its performance in a real application. Experimental measurements on track have demonstrated that the constrained layer damper is properly tuned to the squealing frequency and that there is a significant reduction in noise when the proposed damper is attached to the wheels.
\end{abstract}

\section{State of the Art}

Given the increases in urban railway traffic and tram lines around the world, environmental requirements for railway noise are becoming more and more strict. Reducing noise at the source can be more attractive than erecting noise barriers, but this requires a thorough analysis of noise generation mechanisms as well as methodologies for evaluating the effectiveness of proposed solutions [1].

Extensive work has been done on the vibroacoustics of railway wheels, which is one of the most critical components for railway noise emission [2]. The main sources of wheel noise can be classified as rolling noise, impact noise, or squeal noise, with the last being the most difficult to mitigate.

Wheel squeal is considered to be a phenomenon of instability in wheel vibrations rather than resonance [2-4]. Sufficient positive damping, which is only a small fraction of critical damping, can in fact stabilize vibrations and reduce squeal. Thus, squeal can be eliminated by increasing wheel damping [5].

Different ways of increasing wheel damping have been reported in the literature, and the most important methods are the use of resilient wheels [6-9], ring dampers [6, 10-13], CAF dampers [14-16], and constrained layer dampers, both as a treatment applied to the wheel web $[1,6,8,17-19]$ and as tuned dampers $[1,6,20,21]$.

While other damping solutions act on the entire frequency range, tuned constrained layer dampers (CLD) can be designed to affect only some specific frequencies. They combine metallic sheets with polymeric layers, and their damping is due to the dissipation of energy that occurs through the shear deformation of the polymeric material. Since their damping effect can be concentrated within the frequency ranges of interest, these solutions are more adequate for tackling a range of purposes.

This way of increasing system damping is used in different applications, not only in railway wheels. Several authors have studied the modelling of CLDs from different approaches. Kiehl and Jerzak [22] studied a gun tube damped by a constrained viscoelastic polymer. The system was analysed through a time domain solution, where the Golla-HughesMcTavish method was used to incorporate the viscoelastic properties of the polymer. Alvelid and Enelund [23] developed an interface finite element formulation for the rubber 
in a steel-rubber-steel sandwich plate. Hazard and Bouillard [24] modelled a viscoelastic sandwich plate by using the partition of unity finite element method. Xie and Shepard Jr. [25] distinguished between three types of damping (extension damping, compression damping, and shear damping) to develop an enhanced analytical model of a beam-like structure with constrained layer damping. Martinez-Agirre and Elejabarrieta [26] modelled a constrained layer damping configuration by using a unique layer with homogenised properties and compared the results with a multilayered model.

The optimization of CLDs has also attracted the attention of many researchers. Several studies have been carried out on the spacing effect [27] and the different parameters that can affect the initial transient motion [28] and modal loss factor [29,30]. Even genetic algorithms have been used [31] to optimize the loss factor of the system's first mode of vibration.

Active constrained layer dampers (ACLDs), whose constraining layer is made of a piezoelectric material, have also been studied by different authors. With the goal of emphasizing the potential of passive devices, Cento and Kawiecki [32] applied them to beams and other authors like Gao and Shen [33] and Ro and Baz [34] used them on plates. Ruzzene et al. [35] saw a significant improvement in the damping characteristic by using magnetic constrained layer dampers (MCLD) in attraction.

With respect to railway wheels, Cervello et al. [17] and Nielsen and Fredö [36] studied the application of CLDs on the entire wheel web surface, concluding that noise emission could be significantly reduced. Cervello et al. [17] reduced noise by about $20 \mathrm{~dB}$ in laboratory measurements and by about $10 \mathrm{~dB}$ in the field compared to the standard wheel noise emission. Nielsen and Fredö [36] developed a numerical procedure for optimizing railway wheels in terms of fatigue strength and minimal rolling noise. To improve the wheel design, a constrained layer damping treatment was applied to the web, yielding a $11 \mathrm{~dB}$ reduction in the wheel component for A-weighted rolling noise.

Färm [20] used tuned absorbers as well as ring dampers on a train. They concluded that wheel dampers had an effect not only above $2000 \mathrm{~Hz}$ but also for frequencies as low as $800 \mathrm{~Hz}$, where the rail should be dominating. Cervello and Lombardo [21] also studied tuned absorbers and developed two different systems, one for resilient wheels used on urban tram vehicles and another for freight wheels. They emphasized that the advantage of these solutions is the possibility of concentrating the damping strength at specific frequency bands.

\section{Introduction to the Problem}

The most important and valued advantages of the tram are that it is ecological and sustainable; it coexists in a healthy way with the city and environment. This concept of health also refers to the acoustics, oftentimes one of the most criticized aspects of wheeled vehicles.

The main difficulty for a tram system is the fact that it has to be adapted to the city, meaning to its streets and intersections. Unlike other railway vehicles, curves and routes cannot be designed and instead they have to be shaped to what the city allows. Trams therefore are sometimes forced to draw very small radius curves. Resilient wheels are very often used in tram systems because these wheels tend to dissipate vibrations better and generate lower noise levels. However, resilient wheels can actually suffer of squealing noise [21].

The tram system in the Spanish city of Vitoria is relatively young; it has been running only since late 2008. It has been very successful from the beginning and it is now used by a large number of citizens. Resilient wheels are installed on every bogie of the Vitoria tram. However, because of small radius curves, there is a squeal problem in the $780-800 \mathrm{~Hz}$ frequency range (see Figure 1(a)). Looking at the modal analysis of the resilient wheel (Figure 1(b)), it can be seen that this frequency coincides with the natural frequency of the wheel 0L2 mode (lateral mode with 0 nodal circles and 2 nodal diameters, according to the classification established by Thompson [37]). The use of CLDs appears as a solution to this specific problem.

The use of resilient wheels adds some geometric limitations to the problem. The designed CLD has to meet the available space restrictions. The two shadowed areas in Figure 2 represent the entire space available for attaching the damper. Furthermore, in order to fulfill the safety requirements, the CLDs have to be screwed to the wheel.

The aim of the present work is to design a particular CLD that increases wheel damping in the tram of Vitoria, in order to reduce wheel vibration and its radiated noise. In what follows, the modelling approach adopted to design the damper is presented, together with the evaluation of its performance in the real application.

\section{Material Properties}

CLDs are devices that combine metallic sheets with polymeric layers, and when tuned to the desired frequency they increase the damping of the railway wheel modes due to the dissipation of energy that occurs through the shear deformation of the polymer.

The main part of CLDs is the polymer. The two predominant properties of the polymeric material are loss factor (damping) and stiffness; a polymer with a high damping factor and relatively low stiffness is normally desired for CLD applications.

The choice of the polymer is not easy, and oftentimes a balance between these two properties has to be found. If the polymer is too stiff, little shear deformation occurs, even if its damping factor is very high, which results in low energy dissipation. The structure and the constrained layer become rigidly coupled and the polymer does not deform. On the other hand, if the polymer is too soft, both the structure and the constrained layer become almost uncoupled. The material undergoes large deformations, but it adds little damping since it offers no resistance, resulting in minimal energy dissipation. 


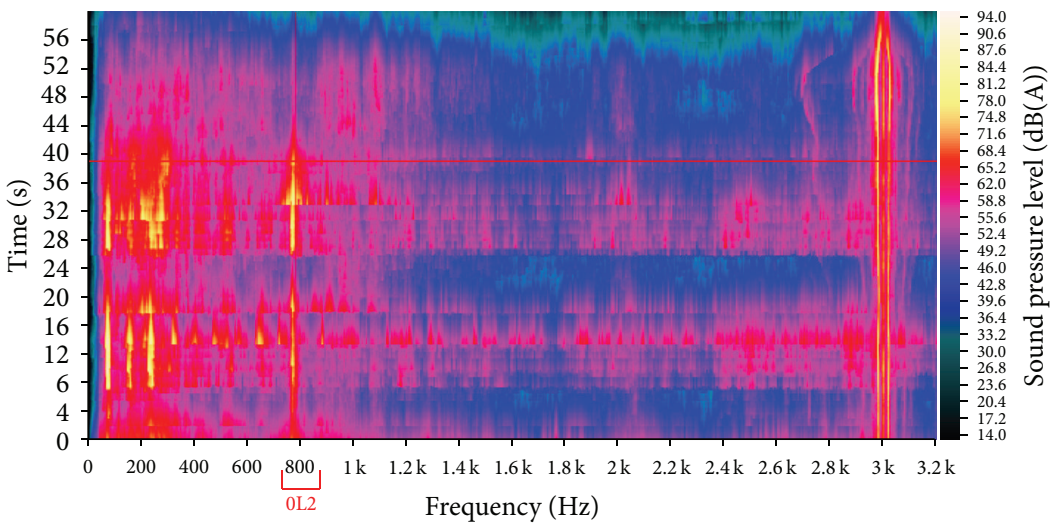

(a) Acoustic measurements at a speed of $5 \mathrm{~km} / \mathrm{h}$

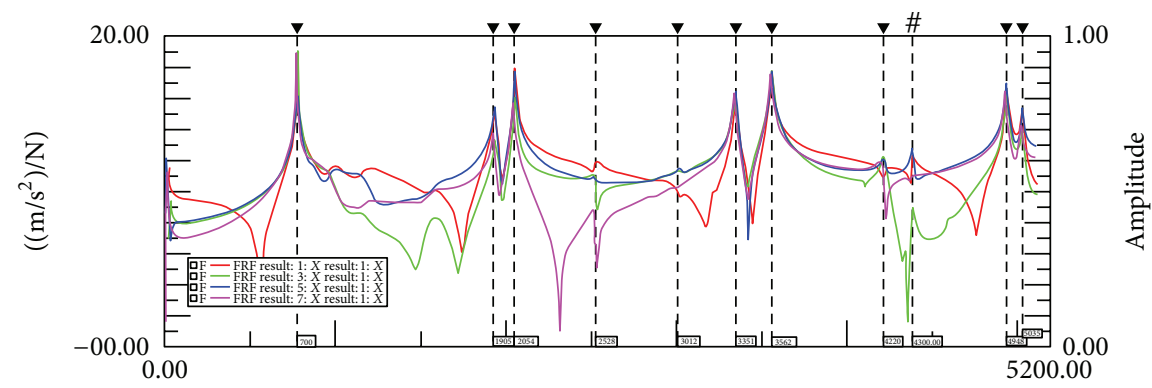

$(\mathrm{Hz})$

(b) Modal analysis of the resilient wheel used in Vitoria's tram

FIGURE 1: Squeal noise generated by the wheel 0L2 mode.

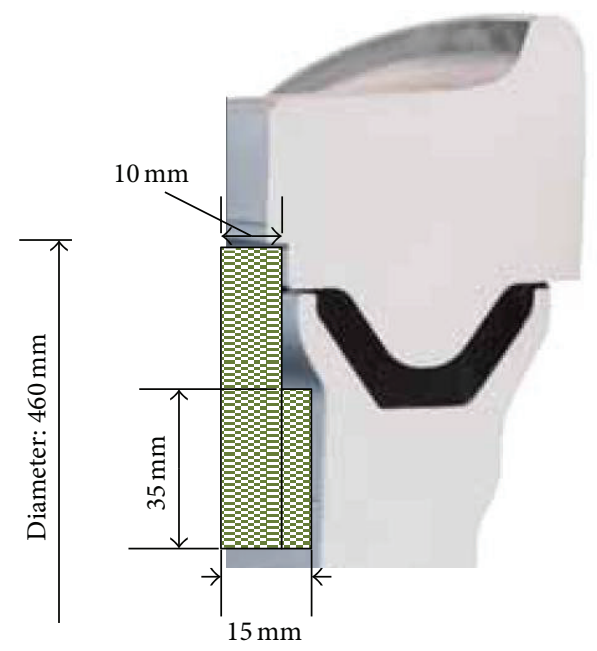

FIgure 2: Geometric limitations to CLD design.

With CLD dampers, viscoelastic materials from the silicone family are normally used. This kind of material provides a good balance between stiffness and loss factor, as it is very soft with a relatively high loss angle (on the order of $15^{\circ}$ ).

In our particular application, the frequency range where the problem appears is relatively high $(780-800 \mathrm{~Hz})$, so material stiffness does not need to be very low and a stiffer material is preferred. Butyl rubber is chosen, which is stiffer than silicone but at the same time presents a higher loss factor, which is always desirable.

Elastomers (as butyl rubbers) are amorphous polymers that exhibit partly elastic and partly viscous behavior. Their molecular structure enables them to undergo large deformations and recover almost completely in unloading. Despite the nonlinear stress-strain relationship that is appreciated when elongations up to several hundred percents are conducted, in many applications elastomers are subjected to only small strains and linear stress-strain relationship is to be considered in that region [38].

Concerning dynamic behaviour, elastomers have properties intermediate between linear elastic solids (that obey Hooke's law-stress is proportional to strain) and ideal viscous liquids (that obey Newton's law-stress is proportional to the rate of change of strain with time). The response of these materials, which act neither as ideal elastic solids nor as ideal liquids, is termed viscoelastic behaviour [38].

When such materials are subjected to dynamic excitation, stress and strain are not in phase; therefore, in addition to the ratio of stress to strain, the phase difference or phase angle is to be determined [38]. Usually the overall response of the material can be expressed in terms of the complex shear modulus [39]:

$$
G^{*}=G_{1}+j G_{2}=G_{1}(1+j \tan \delta),
$$


where $G_{1}$ is the in phase, or storage modulus, and $G_{2}$ is the out of phase, or loss modulus. The loss angle, $\delta$, which is related to the damping or hysteretic energy losses of the material, is given by $\tan \delta=G_{2} / G_{1}$. Both the magnitude $\left|G^{*}\right|$ and the loss angle $\delta$ of viscoelastic compounds are dependent on frequency and temperature in the case of viscoelastic materials [40, 41]. In the case of elastomer materials (as butyl rubber) they might also depend on the amplitude of the applied excitation [38, 39].

The quasi-static, elastic, stress-strain relationship of butyl rubber, together with the dynamic complex shear modulus (and its dependencies), needs to be experimentally characterized in order to develop any theoretical model of a CLD.

The quasi-static stress-strain relationship is determined following indications given by standard ISO 1827 [42]. It is a ramp loading-unloading test conducted at very low speed so that viscous effects are not affecting the results. Specimens are tested in simple shear and, thus, the quasi-static shear modulus is obtained.

Concerning the characterization of the dynamic behavior of butyl rubber, there is no normalized procedure thus far that allows the dynamic shear modulus $G^{*}$ to be determined as a function of frequency and excitation amplitude.

In this study, $G^{*}$ (both the magnitude and loss angle) is determined from experiments carried out on the INSTRON Hydropuls MHF 25l test equipment available in CEIT (Figure 3), which allows samples of viscoelastic and elastomer materials to be tested in a frequency range of up to $400 \mathrm{~Hz}$ and under excitations of different amplitudes, waveforms, and frequencies (following procedures published in ASTM D5992 [43] or ISO 4664-1 [44]).

Material specimens are tested in simple shear, with a sample corresponding to half the specimen for quasi-static measurements suggested in ISO 1827 [42], which is not suitable for the forced nonresonant dynamic simple shear test in the frequency range under study in the present paper. This new configuration overcomes the dynamic problems of the standardized quasi-static sample due to the inertia effect of the two metal parts that connect the four rubber blocks.

\subsection{Determination of Elastic and Dynamic Characteristics of} Butyl Rubber. The indications given in standard ISO 1827 [42] are followed for the determination of elastic shear properties: the test speed is $25 \mathrm{~mm} / \mathrm{min}$, the maximum deformation amplitude is of $50 \%$, the samples are mechanically preconditioned by four cycles, and the fifth cycle is recorded to avoid the Mullins effect [45]. From this last cycle, the force/displacement curve and the elastic shear modulus of the material are calculated. In each cycle the displacement is continuously increased, with a ramp-shaped rise and fall at the test speed.

In order to determine the dynamic shear modulus, two samples are tested in the $0-400 \mathrm{~Hz}$ frequency range and with maximum excitation amplitude of $\pm 1 \mathrm{~mm}$. The tests are carried out by a swept-sine in the specified frequency range. Samples are mechanically preconditioned and the results of the last sweep are recorded.
These results characterize the dependency of the shear modulus magnitude and the loss angle of the material on frequency (up to $400 \mathrm{~Hz}$ ) and amplitude of excitation. The equipment software directly calculates the sample stiffness values $\left(\left|K^{*}\right|\right.$ in $\left.\mathrm{N} / \mathrm{mm}\right)$ and the loss angle (in degrees), by applying the FFT (fast Fourier transform) to the temporal signals of displacement and force in each of the excitation frequencies:

$$
K^{*}\left(w_{o}\right)=\frac{\widetilde{F}\left(w_{o}\right)}{\widetilde{x}\left(w_{o}\right)}\left\{\begin{array}{l}
\left|K^{*}\right|=\frac{\left|\widetilde{F}\left(w_{o}\right)\right|}{\left|\widetilde{x}\left(w_{o}\right)\right|} \\
\text { loss angle }=\frac{180}{\pi} \text { phase }\left(K^{*}\left(w_{o}\right)\right) .
\end{array}\right.
$$

In the previous expression $\widetilde{F}\left(w_{o}\right)$ represents the Fourier transform of the force at the excitation frequency $w_{o}$ and $\widetilde{x}\left(w_{o}\right)$ represents the Fourier transform of the displacement at the same excitation frequency.

Knowing the sample stiffness and the tested sample dimensions, the shear modulus value is evident:

$$
\begin{aligned}
& \left|G^{*}\left(w_{o}\right)\right|=\frac{\left|K^{*}\left(w_{o}\right)\right| \cdot \text { thickness }}{2 \cdot \text { length } \cdot \text { width }}, \\
& \text { loss angle }=\frac{180}{\pi} \text { phase }\left(K^{*}\left(w_{o}\right)\right) .
\end{aligned}
$$

3.2. Results. The slope of the force/displacement loop (loadunload cycle) of a quasi-static test gives the value of the elastic shear modulus. The resulting magnitude values are the following:

(i) $G=3.368 \cdot 10^{5} \mathrm{~Pa}$

(ii) $E=3 G=1.011 \cdot 10^{6} \mathrm{~Pa}$ (incompressibility is assumed).

It has been stated that elastic shear modulus is not dependent on the test speed, at least in the speed range under consideration here.

As for the dynamic behavior, Figure 4 shows the dependence on frequency for both the magnitude $(\mathrm{Pa})$ and the loss angle (degrees) of complex shear modulus for the butyl rubber material when applying a deformation of $2.5 \%$. It is evident that both the amplitude and phase increase with frequency, especially in the first half of the range $0-200 \mathrm{~Hz}$. Above $200 \mathrm{~Hz}$, the stiffness and loss factor maintain almost constant, a tendency that has been reported to continue up until $1000 \mathrm{~Hz}$ [39]. The fact that high loss angle values are achieved is noteworthy: up to $35^{\circ}$ at the highest frequencies.

Material behaviour is also dependent on the applied deformation amplitude (see Figure 5), a behavior common to the majority of the filled elastomers. The lower the deformation amplitude, the higher the shear modulus magnitude, where the values for the lowest deformations are greater than twice the value for the highest tested ones. In terms of the loss angle, it reaches a maximum when the slope of the magnitude is the highest. At the frequency shown in Figure $5(100 \mathrm{~Hz})$ values are between $20^{\circ}$ and $28^{\circ}$, reaching a maximum $\left(28.4^{\circ}\right)$ at deformation amplitude of $5 \%$. 

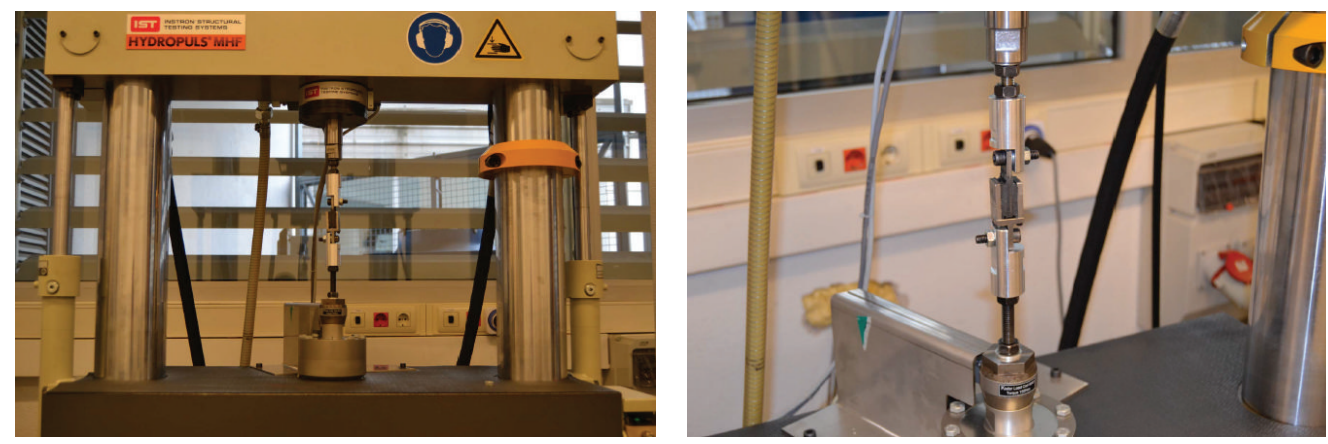

FIGURE 3: INSTROM Hydropuls MHF $25 \mathrm{~L}$ test equipment.

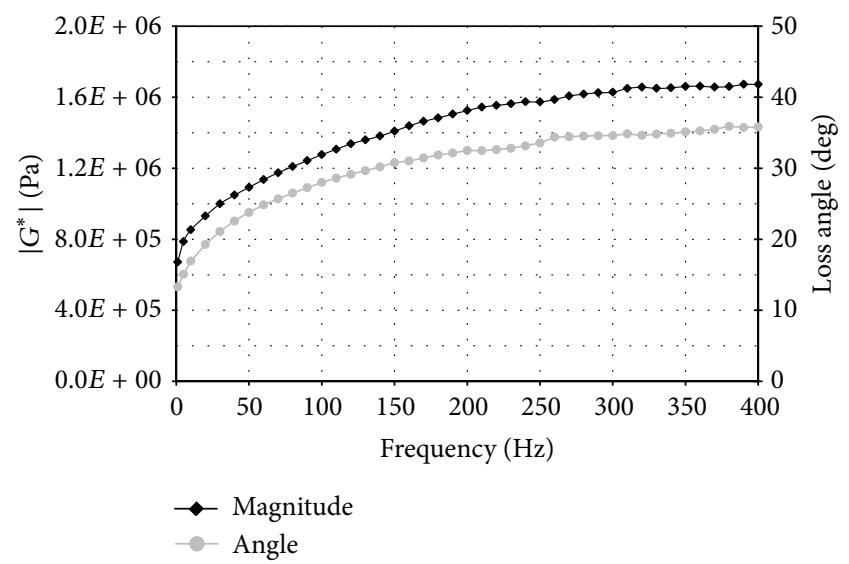

Figure 4: Dynamic test. Strain amplitude $=2.5 \%$. Complex shear modulus.

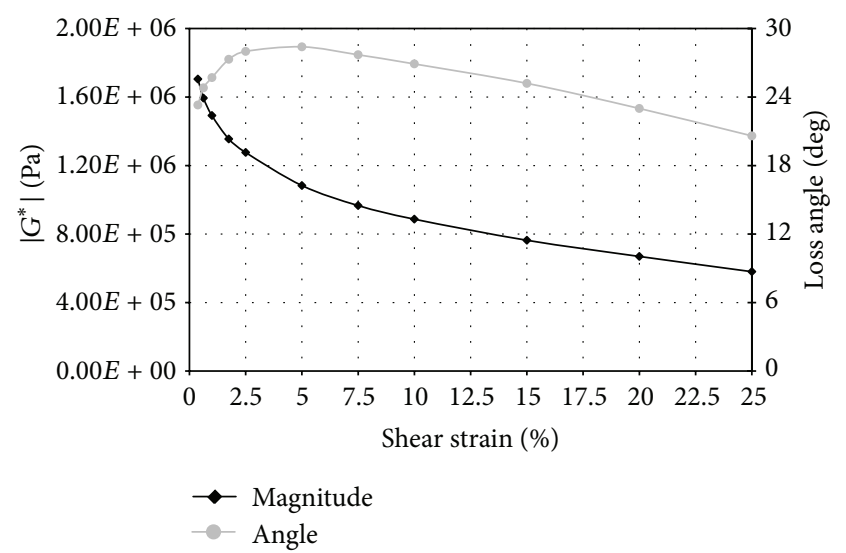

Figure 5: Dynamic test. Frequency $=100 \mathrm{~Hz}$. Dependency of $G^{*}$ with deformation amplitude.

\section{Modelling a CLD}

In what follows, the modelling approach to design a CLD will be described. The finite element method based Abaqus/CAE software is used.

Because of the geometric limitations (Figure 2 shows a scheme of the available space), the number of polymeric layers is limited to two.
4.1. Metallic Sheets. Metallic sheets are modelled with shelltype elements because of their low computational cost. Specifically, 4-node shell-type elements are used. These elements are linear with nonreduced integration.

Shell-type elements have to be modelled without thickness values; instead, the thickness values are introduced in the definition section. Because of this, the real thickness of the sheet should be taken into account in the assembly, leaving an offset so that in reality there is no intersection between the different parts of the model (see $h$ in Figure 6) [46].

4.2. Polymeric Layers. A precise modelling of the polymer is necessary for accurately predicting the behaviour of the tuned CLD. The polymer is the essential part of the device, and as such it has the biggest influence on the results. Therefore, we have decided to model it with brick-type solid elements. More specifically, 20-node hexahedral brick-type elements are used. These elements are quadratic in order to improve accuracy with nonreduced integration.

A fundamental aspect of modelling polymeric layers is the definition of the material itself. According to the results, butyl rubber is a nonlinear viscoelastic material, where the stress response to an excitation is dependent not only on frequency but also on the excitation amplitude. Nevertheless such material behavior is not nowadays available in commercial finite element codes, where only linear viscoelastic material models are implemented. Linear viscoelasticity ignores the dependence of the material properties on the excitation amplitude, considering only the influence of frequency on the response. Although approximate results might be found and uncertainties exist on the excitation value at which material properties should be introduced in the code, linear viscoelasticity has been considered in the definition of butyl rubber. Instead of trying to implement more complex nonlinear material models and/or procedures (see, e.g., [47, 48]) differences in natural frequencies of the CLD will be evaluated by considering different material properties in the material model.

Definition of linear viscoelastic material model in finite element codes requires the introduction of both the measured quasi-static (elastic, long-term) shear modulus and the complex, frequency-dependent, dynamic shear modulus of the material (both measured in Section 3). The density of material (also needed to perform dynamic calculations) is $1000 \mathrm{~kg} / \mathrm{m}^{3}$. 


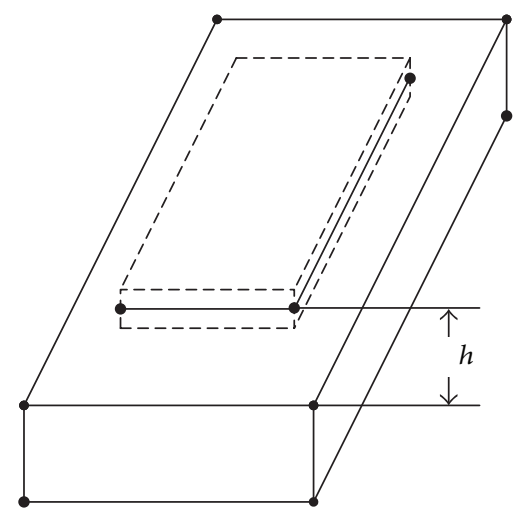

FIGURE 6: Shell-solid interaction.

Concerning the storage and loss modulus, they should be defined in a range of interest for the application (200$1000 \mathrm{~Hz}$ in our case, as the natural frequency of interest is around $800 \mathrm{~Hz}$ ). At a particular excitation level a constant value of the magnitude and loss factor are introduced in the indicated frequency range, according to the results shown in Section 3.2. An excitation shear strain of $2.5 \%$ is considered as nominal value for the design purposes.

\section{Modelling and Design of the CLD}

Using all the information from the previous section, a first design of the CLD is made. Due to economic reasons, the thicknesses of the metallic sheets have to be adjusted to the discrete values offered by manufacturers. Given these limitations and the geometric limitations that arise from using resilient wheels, the thicknesses of the base metallic sheet (attached to the wheel), a first polymeric layer, and upper metallic sheet are defined.

On the other hand, to take advantage of all the available space (see the two shadowed areas in Figure 2), another polymeric layer and another metallic sheet are attached under the base, in a cantilever way. In doing so, a greater damping strength can be added to the damper. Figure 7 shows the first design of the CLD, which shows the offset left between the shell-type metallic layers and the brick-type polymeric sheets.

It was explained in the introductory section that dampers have to be screwed to the wheel and Figure 2 shows that a large part of them will be cantilevered. This fact introduces uncertainties with regard to the boundary conditions in the theoretical model. Some fictitious springs are attached to certain nodes of the damper (to those nodes where the screws take part) and, being joined to a fixed point, determine the stiffness of the linkage between the CLD and the wheel. The springs act in the three dimensions, but it is reasonable to define a lower stiffness value for the vertical direction ( $Z$ axis, perpendicular to the base) than for the two other directions, as screws are stiffer in those two directions than in their longitudinal direction. Even if the exact stiffness values cannot be known, it is estimated that they will be of the order of $10^{7} \mathrm{~N} / \mathrm{m}$. The real values are validated and adjusted by comparing theoretical/experimental results of a manufactured CLD. Therefore, one unit is built and tested.

The validation consists of laying the tram resilient wheel on an elastic support and attaching the damper to it (see Figure 8). In this sense, the real coupling between the wheel and the CLD is represented and the elastic support ensures that its frequencies do not interfere with those of the damper.

As damper efficiency depends mainly on tuning to the natural frequencies of the wheel that are to be damped, the principal parameters to control and validate are the natural frequencies of the damper. An accelerometer is placed on the upper sheet of the CLD and a dynamometric hammer is used for excitation, and the natural frequencies of the CLD are related to the peaks of the extracted acceleration/force FRF results.

For a good theoretical-experimental validation, the effect of the accelerometer also has to be taken into account in the theoretical model, so a mass of $5.6 \mathrm{~g}$ (the weight of the accelerometer used) is placed at the point where the accelerometer is located. A punctual force is applied at the point where the hammer hits the CLD in experiments.

Figure 9 shows the theoretical model, where impact and measurement points are highlighted.

Comparisons between experimental and calculated acceleration results lead to the following values for the springs in the attachment of the CLDs:
(i) $K_{x}=K_{y}=5 \cdot 10^{7} \mathrm{~N} / \mathrm{m}$
(ii) $K_{z}=1 \cdot 10^{7} \mathrm{~N} / \mathrm{m}$.

Assuming these values, there is good agreement between the experimentally measured natural frequencies and the theoretically calculated ones (see Table 1).

Due to the low weight of the CLD, the mass of the accelerometer influences the results. In operating conditions, when the CLD is attached to the wheel, there is no accelerometer on it, so its natural frequencies will be different. If the punctual mass is removed from the theoretical model, the natural frequencies of the damper change slightly, by about $2 \%$.

We have also realized that the second mode of the CLD has a higher damping strength than the first one. Following the same idea as the Modal Strain Energy (MSE) method [49], the elastic strain energy of the polymer in both modes is compared, and it is seen that the second mode dissipates higher energy than the first one. Thus, we have decided to tune the damper's second mode with the wheel 0L2 mode in order to achieve the highest damping level.

Once the CLD model is validated, the final design has to be made by altering some design variables. From the geometric point of view, if the thickness of the metallic sheets and the polymeric layers are defined, the only possible variation will be that of the polymeric length. In Figure 7 it can be seen that the upper metallic sheet and polymeric layer have different lengths; that is to say that the upper sheet is cantilevered. The length of polymeric layer is the variable that defines the CLD's final design.

Polymeric layer's length is changed until the natural frequency of the second mode of the damper coincides with 
TABLE 1: Experimental and theoretical eigenfrequencies of the CLD.

Experimental frequency $\quad$ Theoretical frequency

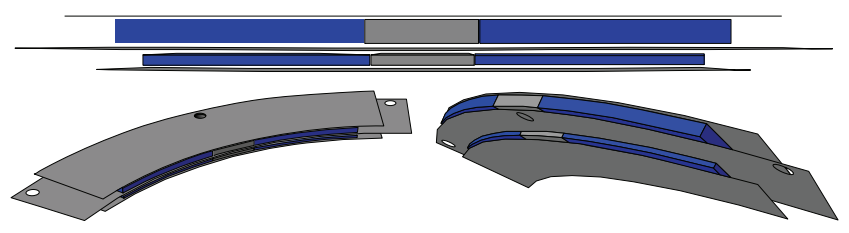

FIgURE 7: Theoretical model of the CLD.

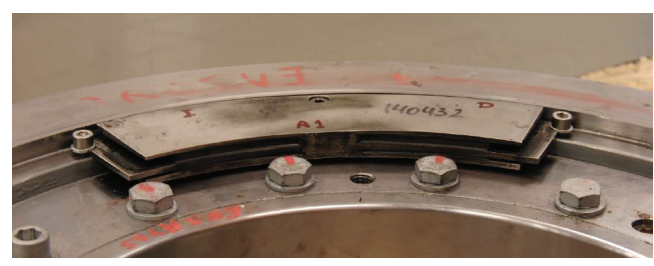

FIGURE 8: Real damper attached to the tram wheel.

the frequency of the 0L2 mode. Figure 10 shows the theoretical acceleration/force frequency response function (FRF) for the final CLD when no accelerometer is attached to it. It can be seen that the second natural frequency is slightly lower than the 0L2 mode frequency. Nevertheless, this frequency can be increased easily (if necessary) by manually eliminating a bit of polymer. By ensuring the tuning to the natural frequency of the wheel, a significant increase in modal damping and thus good soundproofing can be expected when this CLD is attached to the tram wheel.

Concerning the definition of the material in the finite element model, which ignores the excitation amplitude dependency of butyl rubber, some calculations have been conducted changing material properties. The geometry already defined for the CLD has been maintained and the storage and loss modulus have been changed in the definition of the material in the finite element code, introducing values measured at excitation amplitudes different from the nominal shear strain of $2.5 \%$ (adopted for the definition of the geometry of the CLD). When material properties are defined at a shear strain amplitude of $25 \%$ (the maximum amplitude tested) the natural frequency of the second mode decreases only $20 \mathrm{~Hz}$, from $760 \mathrm{~Hz}$ to $740 \mathrm{~Hz}$, which is also close to the resonant frequency of the wheel that needs to be damped.

Six CLDs have been manufactured and attached to a wheel, covering all the perimeter of the rim. The damping added to the 0L2 mode has been experimentally evaluated. The tram wheel is placed on a rubber base support and it rests horizontally. The support adds a small degree of rigidity, so the natural frequencies of the test-bench differ from those of the wheel. In order to analyze the wheel 0L2 mode, an accelerometer is located on the rim's lateral surface and excitations are induced with a dynamometric hammer to acquire acceleration/force FRFs. Damping ratios are calculated from the FRFs using TestLab software by LMS. Through the least squares complex exponential technique, damping ratios can be determined for the undamped (without any damper) and damped wheel cases. Measurements carried out in laboratory show that, after attaching 6 dampers on the wheel, the damping ratio of the wheel 0L2 mode increases from $0.17 \%$ (the damping for the undamped wheel case) to $0.48 \%$. Wheel modal frequencies do not vary considerably after installing the dampers, proving that the weight added by the six dampers is negligible compared to that of the wheel. These results verify that the designed and manufactured damper is correctly tuned to the wheel mode.

\section{Experimental Measurements on Track}

Performance of designed and manufactured CLD is evaluated through experimental measurements on track.

The tram in Vitoria is composed of three bogies (see scheme in Figure 11) - the first and the third are poweredand they can circulate in both directions. The squeal noise normally appears at a higher level in those wheels that are motorized, so we have decided to use these two bogies for our comparison. In this way, by installing the CLDs on the wheels (6 dampers on each wheel-see Figure 12) of the first bogie, a comparison can be made between the damped wheels and the free wheels (wheels with no dampers) of the third bogie.

The tram is driven along a narrow curve (with an approximately $25 \mathrm{~m}$-radius) where squeal noise is generated in operating conditions (see Figure 13(a)). The average speed 


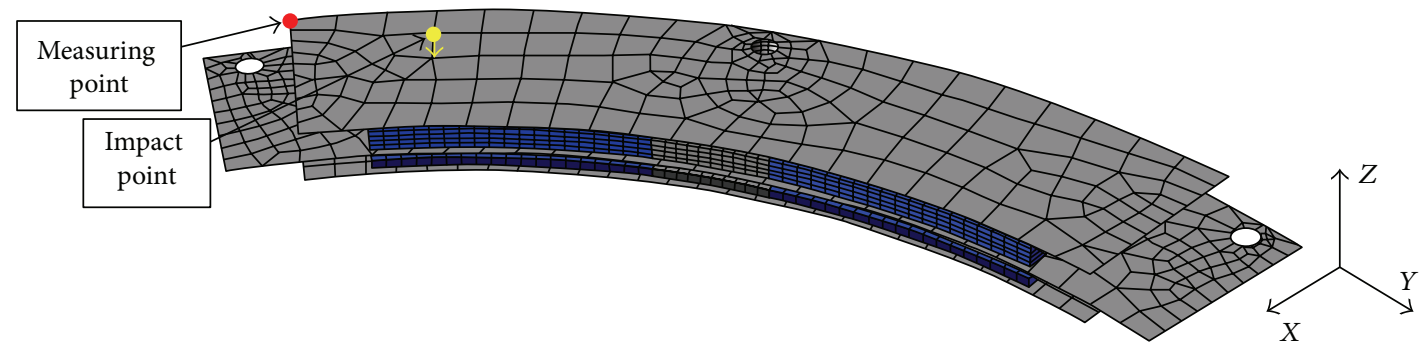

FIGURE 9: Theoretical model of the CLD with the impact and measurement points.

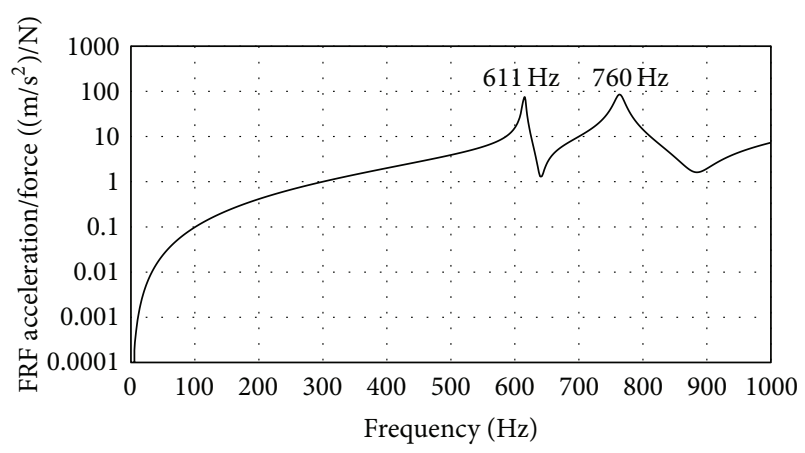

FIgURE 10: Acceleration results for the final CLD.

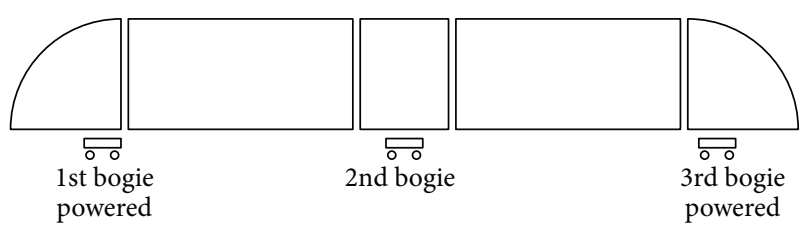

FIGURE 11: Scheme of the configuration of the tram.

during the measurements is $15-20 \mathrm{~km} / \mathrm{h}$. Three microphones are placed in the interior of the curve $1.2 \mathrm{~m}$ from the inner rail and $1 \mathrm{~m}$ from the ground, which coincides with the railhead which is embedded in the street (see Figure 13(b)).

17 passes are made in both directions and acoustic pressure results are collected. The three microphones present the same tendency and results are very similar in both directions. From all the collected results, Figure 14 shows in three-dimensional graphs the most representative ones measured by one of the microphones. The horizontal axis shows which frequencies are the most responsible for squeal, the right vertical axis highlights which bogie generates higher noise levels, and the left vertical axis defines noise level scale.

In order to quantify the noise reduction achieved with this configuration, Figure 15 shows the sound pressure measured during two different passes. The solid line corresponds to the highest peak in the first bogie (with damped wheels) and the dotted line corresponds to the highest peak in the third bogie (with no damping solution).

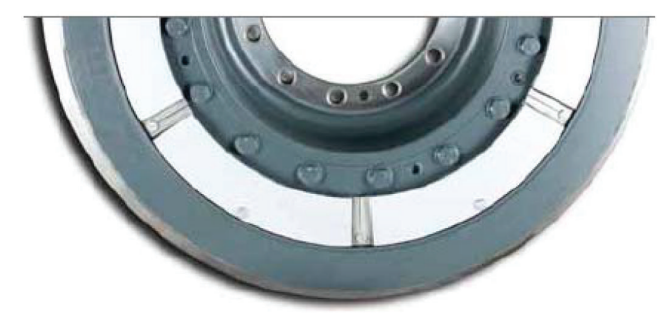

FIGURE 12: Tram wheel with 6 dampers installed on it.

\section{Discussion}

Looking at the results, it can be concluded that the highest noise levels are generated in the $780-800 \mathrm{~Hz}$ frequency range, which is in fact the frequency of the wheel 0L2 mode, as expected. According to Figure 14, bogie 3 generates higher noise levels than bogie 1 , so it can be concluded that damped wheels are quieter than free wheels. This means that the dampers designed and presented here are correctly tuned to the $0 \mathrm{~L} 2$ mode and are thus able to decrease the squeal noise levels.

According to Figure 15, there is a difference of approximately $25 \mathrm{~dB}$ between the noise levels generated by the first and the third bogies. This noise decrease is due to the presence of the CLDs, which also verifies that the dampers are correctly tuned to the 0L2 mode and that they are able to significantly decrease the squeal noise levels. In addition to this, the sound pressure level also drops at around $1600 \mathrm{~Hz}$ in Figure 15. It is another benefit with the CLDs installed.

In summary, these results confirm the effectiveness of the CLDs that have been designed and manufactured in the present paper.

\section{Conclusions}

Even though resilient wheels are installed in every bogie, Vitoria's tram has squeal problems in some small radius curves. The squeal is generated at $780-800 \mathrm{~Hz}$, and it has been demonstrated that it coincides with the wheel 0L2 mode. Since tuned CLDs can be designed to concentrate their damping strength at particular frequency ranges, the aim of this work has been to model and design a CLD specifically to eliminate this squeal noise. 


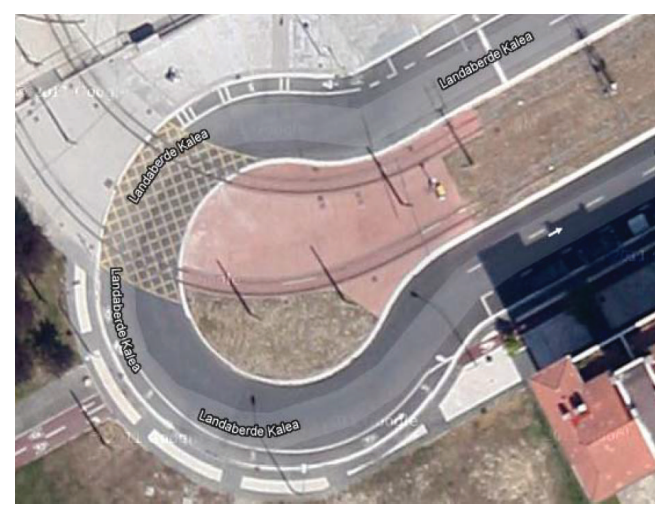

(a) Curve where measurements are carried out

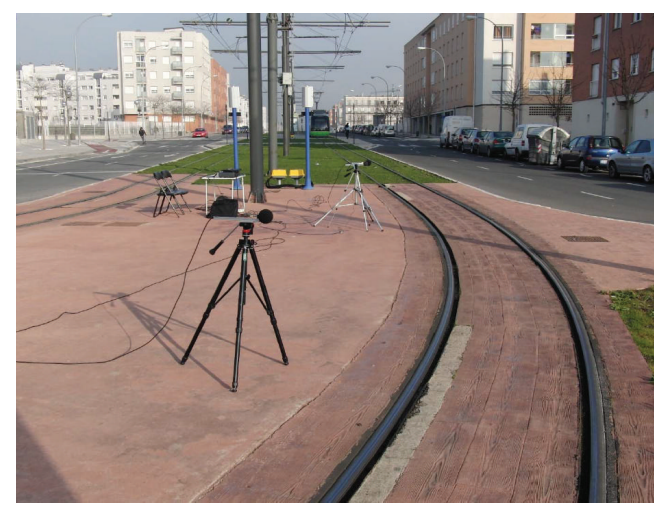

(b) Location of the microphones

FIGURE 13: Track measurements.

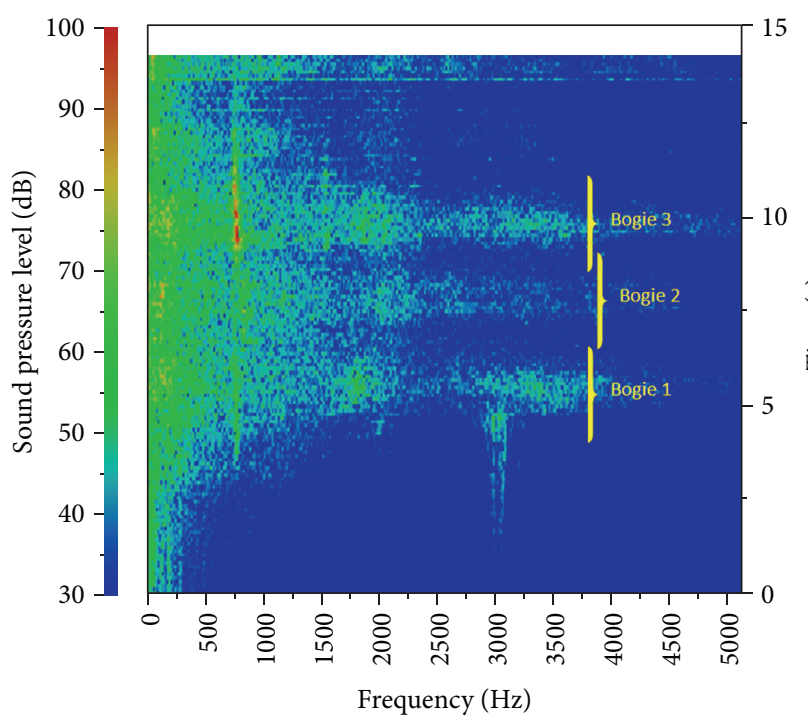

(a)

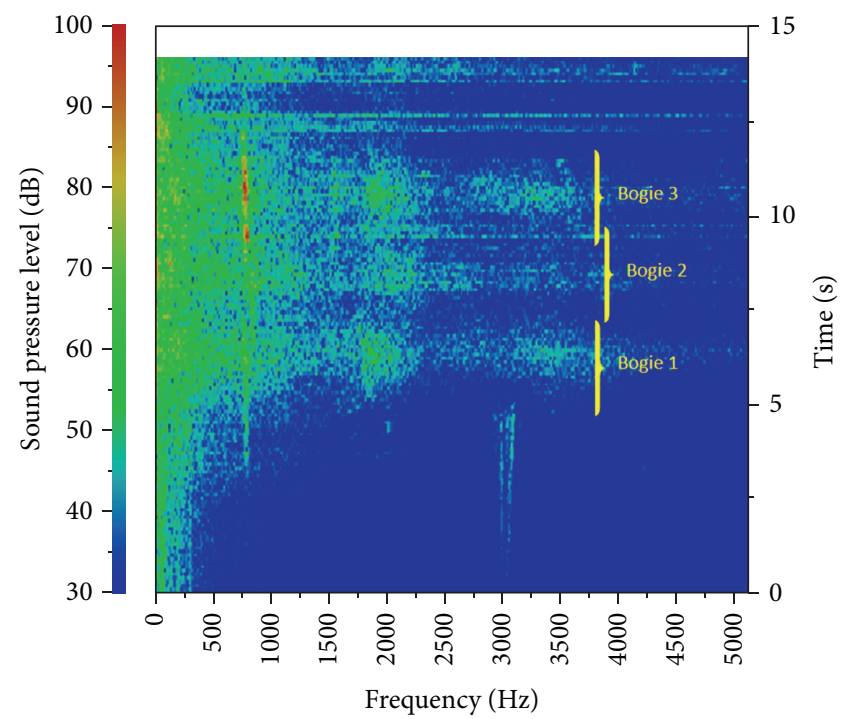

(b)

FIGURE 14: Experimental measurements on track for two different passes.

Butyl rubber is used as the polymeric material in the CLD, and conventional steel as the metallic material for the sheets. The two predominant properties of the polymer, stiffness and loss factor (damping), are experimentally determined by quasi-static and dynamic tests carried out on some samples.

After characterizing the butyl rubber, the model of the CLD is developed. Metallic sheets are modelled with shelltype elements, whereas for polymeric layers brick-type solid elements are used. To keep both parts from intersecting, offsets equal to half of the thickness of the shell-type elements remain.

The dynamic behavior of the CLD model has been proved to be very dependent on the boundary conditions. Thus, the CLD is manufactured in order to carry out dynamic experiments on it, and in parallel, the boundary conditions are adjusted to match the calculations with experimental results. Once the model is validated, the damper design is improved in order to damp the 0L2 mode of the tram wheel and the final CLD design is manufactured.
Experimental on track measurements are carried out where a bogie equipped with free wheels (with no damping solution) and a bogie equipped with damped wheels (with six dampers each wheel) are compared. The results show that a decrease of $25 \mathrm{~dB}$ has been achieved.

As a result, the objective of this project has been met: a proper CLD that reduces squeal noise in the tram system in the city of Vitoria has been designed, manufactured, and tested. With all these results, it can be concluded that a significant noise reduction can be achieved by using a properly designed CLD. This methodology can be applied to similar problems of squeal noise in urban trams.

\section{Conflict of Interests}

The authors declare that there is no conflict of interests regarding the publication of this paper. 


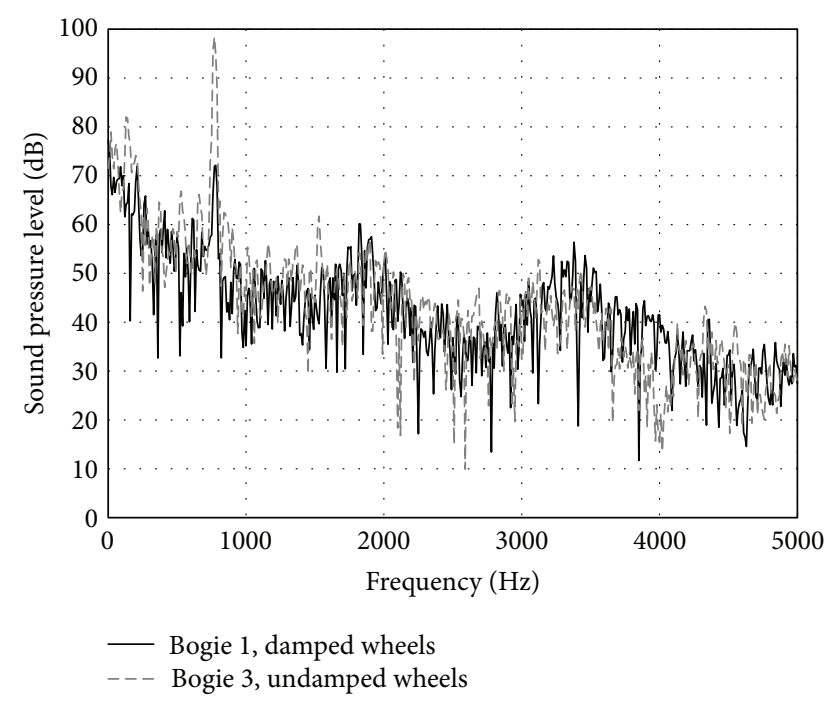

(a)

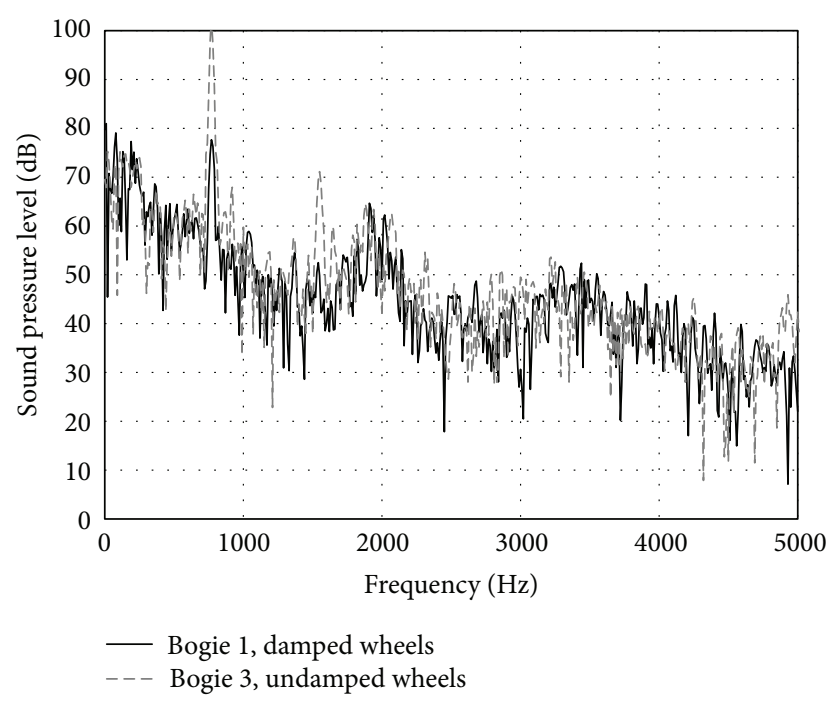

(b)

FIGURE 15: Experimental sound pressure for two different passes.

\section{Acknowledgment}

This work is part of the Research Project ecoTRANS, led by CAF, which is partially funded by the Spanish MICINN (Ministry of Science and Innovation) through the CENIT Programme.

\section{References}

[1] C. Talotte, P.-E. Gautier, D. J. Thompson, and C. Hanson, "Identification, modelling and reduction potential of railway noise sources: a critical survey," Journal of Sound and Vibration, vol. 267, no. 3, pp. 447-468, 2003.

[2] D. Thompson and C. Jones, "Handbook of railway vehicle dynamics," in Noise and Vibration from Railway Vehicles, pp. 279-325, CRC Press, London, UK, 2006.

[3] M. J. Rudd, "Wheel/rail noise-part II: wheel squeal," Journal of Sound and Vibration, vol. 46, no. 3, pp. 381-394, 1976.

[4] H. Sakamoto, "An analytical model for the natural frequencies of a railway wheel and comparison with experimental results," Proceedings of the Institution of Mechanical Engineers, Part F: Journal of Rail and Rapid Transit, vol. 221, no. 3, pp. 391-398, 2007.

[5] M. A. Heckl, "Curve squeal of train wheels: unstable modes and limit cycles," Proceedings of the Royal Society A, vol. 458, no. 2024, pp. 1949-1965, 2002.

[6] L. G. Kurzweil, "Wheel/rail noise-means for control," Journal of Sound and Vibration, vol. 87, no. 2, pp. 197-200, 1983.

[7] P. Bouvet, N. Vincent, A. Coblentz, and F. Demilly, "Optimization of resilient wheels for rolling noise control," Journal of Sound and Vibration, vol. 231, no. 3, pp. 765-777, 2000.

[8] C. J. C. Jones and D. J. Thompson, "Rolling noise generated by railway wheels with visco-elastic layers," Journal of Sound and Vibration, vol. 231, no. 3, pp. 779-790, 2000.

[9] H. Claus and W. Schiehlen, "Dynamic stability and random vibrations of rigid and elastic wheelsets," Nonlinear Dynamics, vol. 36, no. 2-4, pp. 299-311, 2004.
[10] J. F. Brunel, P. Dufrénoy, and F. Demilly, "Modelling of squeal noise attenuation of ring damped wheels," Applied Acoustics, vol. 65, no. 5, pp. 457-471, 2004.

[11] J. F. Brunel, P. Dufrénoy, M. Naït, J. L. Muñoz, and F. Demilly, "Transient models for curve squeal noise," Journal of Sound and Vibration, vol. 293, no. 3-5, pp. 758-765, 2006.

[12] F. Létourneaux, J. F. Cordier, F. Poisson, and N. Douarche, "High speed railway noise: assessment of mitigation measures," in Noise and Vibration Mitigation for Rail Transportation Systems, B. Schulte-Werning, D. Thompson, P.-E. Gautier et al., Eds., vol. 99 of Notes on Numerical Fluid Mechanics and Multidisciplinary Design, pp. 56-62, Springer, Berlin, Germany, 2008.

[13] J. Brunel, P. Dufrénoy, and F. Demilly, "Numerical approach for the attenuation of squeal noise of railway wheels in narrow curves," in Proceedings of the 8th International Conference on Contact Mechanics and Wear of Rail/Wheel Systems (CM '09), Firenze, Italy, 2009.

[14] C. y Auxiliar de Ferrocarriles S.A. (CAF), “2 130 952. Sistema de amortiguamiento de ruido en ruedas ferroviarias," 1999.

[15] I. López Arteaga, Theoretical and experimental analysis of ringdamped railway wheels [Ph.D. thesis], Tecnun-University of Navarra, Navarra, Spain, 1998.

[16] I. López, J. M. Busturia, and H. Nijmeijer, "Energy dissipation of a friction damper," Journal of Sound and Vibration, vol. 278, no. 3, pp. 539-561, 2004.

[17] S. Cervello, G. Donzella, A. Pola, and M. Scepi, "Analysis and design of a low-noise railway wheel," Proceedings of the Institution of Mechanical Engineers, Part F: Journal of Rail and Rapid Transit, vol. 215, no. 3, pp. 179-192, 2001.

[18] A. Bracciali, "Damped wheels as an efficient measure to reduce railway noise," in Proceedings of the Euronoise, 2003.

[19] A. Bracciali, S. Cervello, and P. Gatti, "Acoustic effectiveness of damped wheels and impact on life-cycle cost of different typologies of passenger trains," in Noise and Vibration Mitigation for Rail Transportation Systems, B. Schulte-Werning, D. Thompson, P.-E. Gautier et al., Eds., vol. 99 of Notes on Numerical Fluid Mechanics and Multidisciplinary Design, pp. 257-263, Springer, Berlin, Germany, 2008. 
[20] J. Färm, "Evaluation of wheel dampers on an intercity train," Journal of Sound and Vibration, vol. 267, no. 3, pp. 739-747, 2003.

[21] S. Cervello and F. Lombardo, "Development of a modular damping system against wheel noise emission for freight and urban transport vehicles," in Proceedings of the 56th UITP World Congress, International Association of Public Transport, Rome, Italy, 2005.

[22] M. Z. Kiehl and C. P. T. W. Jerzak, "Modeling of passive constrained layer damping as applied to a gun tube," Shock and Vibration, vol. 8, no. 3-4, pp. 123-129, 2001.

[23] M. Alvelid and M. Enelund, "Modelling of constrained thin rubber layer with emphasis on damping," Journal of Sound and Vibration, vol. 300, no. 3-5, pp. 662-675, 2007.

[24] L. Hazard and P. Bouillard, "Structural dynamics of viscoelastic sandwich plates by the partition of unity finite element method," Computer Methods in Applied Mechanics and Engineering, vol. 196, no. 41-44, pp. 4101-4116, 2007.

[25] Z. Xie and W. S. Shepard Jr., "An enhanced beam model for constrained layer damping and a parameter study of damping contribution," Journal of Sound and Vibration, vol. 319, no. 3-5, pp. 1271-1284, 2009.

[26] M. Martinez-Agirre and M. J. Elejabarrieta, "Characterisation and modelling of viscoelastically damped sandwich structures," International Journal of Mechanical Sciences, vol. 52, no. 9, pp. 1225-1233, 2010, Special Issue on Advances in Materials and Processing Technologies.

[27] H. Zheng, X. M. Tan, and C. Cai, "Damping analysis of beams covered with multiple PCLD patches," International Journal of Mechanical Sciences, vol. 48, no. 12, pp. 1371-1383, 2006.

[28] D. Granger and A. Ross, "Effects of partial constrained viscoelastic layer damping parameters on the initial transient response of impacted cantilever beams: experimental and numerical results," Journal of Sound and Vibration, vol. 321, no. 1-2, pp. 45-64, 2009.

[29] Z. Ling, X. Ronglu, W. Yi, and A. El-Sabbagh, "Topology optimization of constrained layer damping on plates using Method of Moving Asymptote (MMA) approach," Shock and Vibration, vol. 18, no. 1-2, pp. 221-244, 2011.

[30] W. Zheng, Y. Lei, S. Li, and Q. Huang, “Topology optimization of passive constrained layer damping with partial coverage on plate," Shock and Vibration, vol. 20, pp. 199-211, 2013.

[31] M. A. Al-Ajmi and R. I. Bourisli, "Optimum design of segmented passive-constrained layer damping treatment through genetic algorithms," Mechanics of Advanced Materials and Structures, vol. 15, no. 3-4, pp. 250-257, 2008.

[32] P. F. Cento and G. Kawiecki, "Finite element modeling of segmented active constrained damping layers including bonding layer effect," Journal of Vibration and Control, vol. 8, no. 6, pp. 805-832, 2002.

[33] J. Gao and Y. Shen, "Vibration and damping analysis of a composite plate with active and passive damping layer," Applied Mathematics and Mechanics, vol. 20, no. 10, pp. 1075-1086, 1999.

[34] J. Ro and A. Baz, "Optimum placement and control of active constrained layer damping using modal strain energy approach," Journal of Vibration and Control, vol. 8, no. 6, pp. 861-876, 2002.

[35] M. Ruzzene, J. Oh, and A. Baz, "Finite element modelling of magnetic constrained layer damping," Journal of Sound and Vibration, vol. 236, no. 4, pp. 657-682, 2000.

[36] J. C. O. Nielsen and C. R. Fredö, "Multi-disciplinary optimization of railway wheels," Journal of Sound and Vibration, vol. 293, no. 3-5, pp. 510-521, 2006.
[37] D. J. Thompson, "Wheel-rail noise generation, part II: wheel vibration," Journal of Sound and Vibration, vol. 161, no. 3, pp. 401-419, 1993.

[38] A. Gent, Engineering with Rubber: How to Design Rubber Components, Hanser, 2001.

[39] P. B. Lindley, Engineering Design with Natural Rubber, Natural Rubber Producers' Research Association, London, UK, 1970.

[40] A. D. Nashif, D. I. G. Jones, and J. P. Henderson, Vibration Damping, John Wiley \& Sons, New York, NY, USA, 1985.

[41] D. I. G. Jones, Handbook of Viscoelastic Vibration Damping, John Wiley \& Sons, 2001.

[42] ISO 1827, "Rubber, vulcanized or thermoplastic. Determination of modulus in shear or adhesion to rigid plates. Quadruple Shear Method," 1991.

[43] ASTM D5992, "Standard Guide for Dynamic Testing of Vulcanized Rubber and Rubber-Like Materials Using Vibratory Methods," 2011.

[44] ISO 4664-1, "Rubber, vulcanized or thermoplastic. Determination of dynamic properties. Part 1: general guidance," 2005.

[45] L. Mullins, "Softening of rubber by deformation," Rubber Chemistry and Technology, vol. 42, pp. 339-362, 1969.

[46] “Getting Started with ABAQUS version 6.4," 2003.

[47] N. Gil-Negrete, J. Vinolas, and L. Kari, "A Nonlinear rubber material model combining fractional order viscoelasticity and amplitude dependent effects," Journal of Applied Mechanics, vol. 76, no. 1, pp. 1-9, 2009.

[48] N. Gil-Negrete, J. Viñolas, and L. Kari, "A simplified methodology to predict the dynamic stiffness of carbon-black filled rubber isolators using a finite element code," Journal of Sound and Vibration, vol. 296, no. 4-5, pp. 757-776, 2006.

[49] E. E. Ungar and E. M. Kervin Jr., "Loss factors of viscoelastic systems in terms of energy concepts," Journal of the Acoustical Society of America, vol. 34, no. 7, pp. 954-957, 1962. 

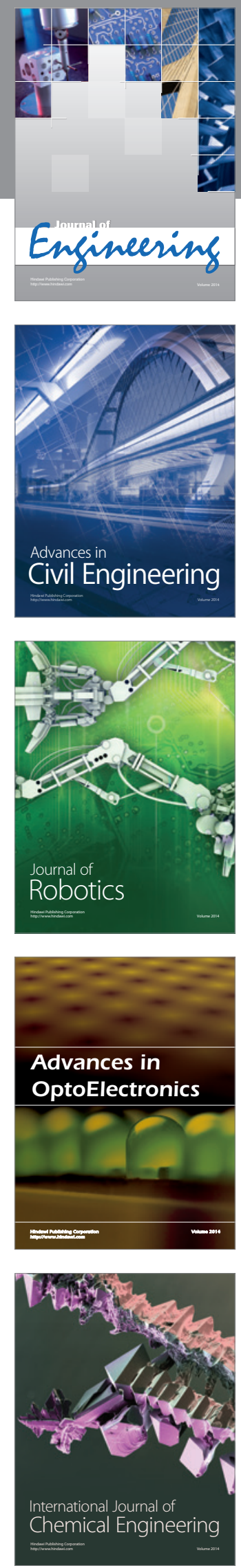

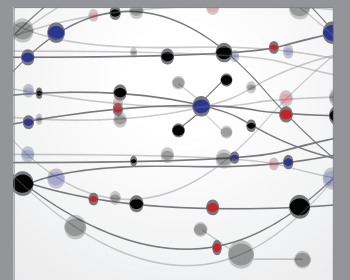

The Scientific World Journal
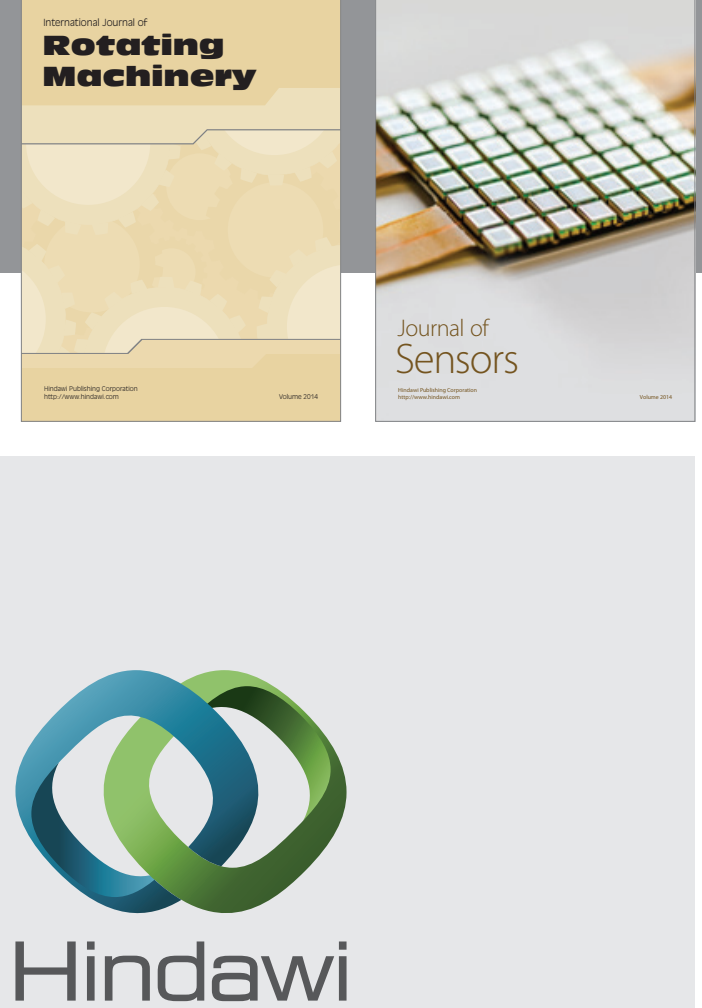

Submit your manuscripts at http://www.hindawi.com
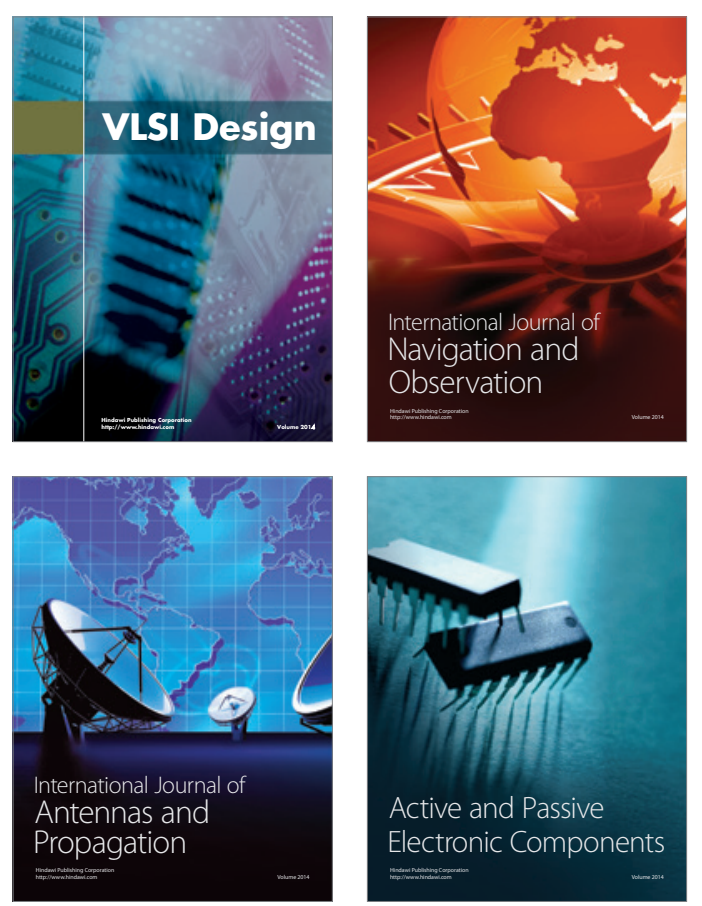
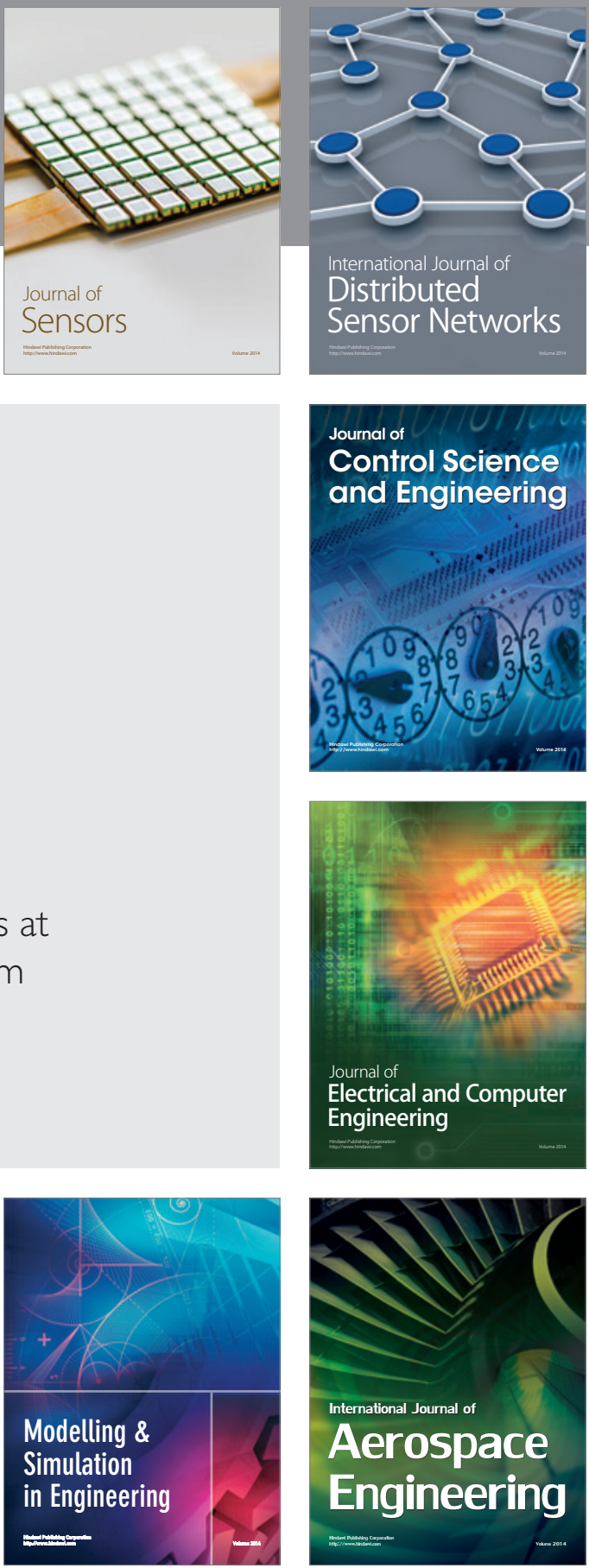

Journal of

Control Science

and Engineering
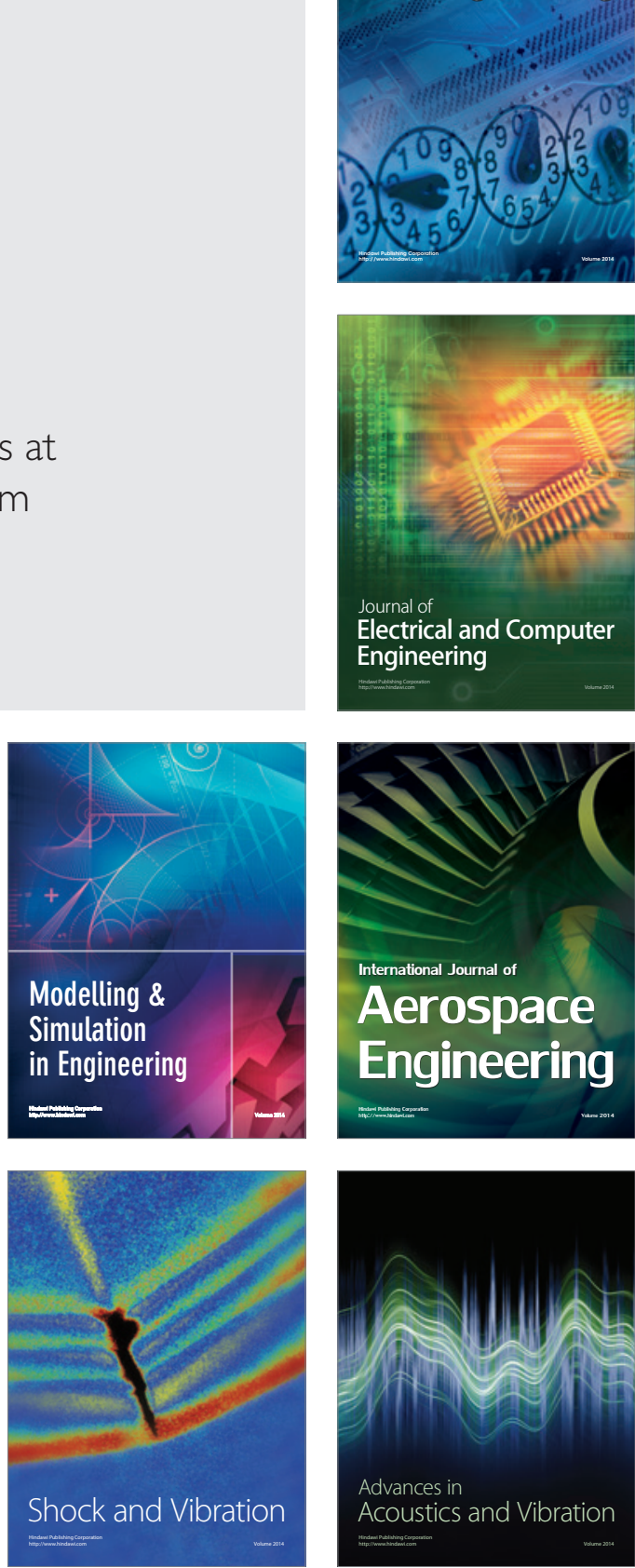